\title{
Condensed tannins in the gastrointestinal tract of cattle after sainfoin (Onobrychis viciifolia) intake and their possible relationship with anthelmintic effects
}

Article

Accepted Version

Desrues, O., Mueller-Harvey, I., Pellikaan, W. F., Enemark, H. L. and Thamsborg, S. M. (2017) Condensed tannins in the gastrointestinal tract of cattle after sainfoin (Onobrychis viciifolia) intake and their possible relationship with anthelmintic effects. Journal of Agricultural and Food Chemistry, 65 (7). pp. 1420-1427. ISSN 0021-8561 doi: https://doi.org/10.1021/acs.jafc.6b05830 Available at https://centaur.reading.ac.uk/68667/

It is advisable to refer to the publisher's version if you intend to cite from the work. See Guidance on citing.

To link to this article DOI: http://dx.doi.org/10.1021/acs.jafc.6b05830

Publisher: American Chemical Society

All outputs in CentAUR are protected by Intellectual Property Rights law, including copyright law. Copyright and IPR is retained by the creators or other copyright holders. Terms and conditions for use of this material are defined in the End User Agreement. 


\section{www.reading.ac.uk/centaur}

\section{CentAUR}

Central Archive at the University of Reading

Reading's research outputs online 
Condensed Tannins in the Gastrointestinal Tract of Cattle after Sainfoin

(Onobrychis viciifolia) Intake and their Possible Relationship with Anthelmintic

\section{Effects}

Olivier Desrues ${ }^{1 \#}$, Irene Mueller-Harvey², Wilbert F. Pellikaan ${ }^{3}$, Heidi L. Enemark ${ }^{4,5}$ and Stig M. Thamsborg ${ }^{1}$

${ }^{1}$ Veterinary Parasitology Group, Department of Veterinary Disease Biology, University of Copenhagen, Dyrlægevej 100, DK-1870 Frederiksberg C, Denmark

${ }^{2}$ Chemistry and Biochemistry Laboratory, School of Agriculture, Policy and Development, University of Reading, Reading RG6 6AT, UK

3 Animal Nutrition Group, Wageningen University \& Research, PO Box 338, $6700 \mathrm{AH}$ Wageningen, The Netherlands.

${ }^{4}$ Section for Bacteriology, Pathology and Parasitology, National Veterinary Institute, Technical University of Denmark, Bülowsvej 27, DK-1870 Frederiksberg C, Denmark ${ }^{5}$ Norwegian Veterinary Institute, PO Box 750 Sentrum, N-0106 Oslo, Norway

\# Corresponding author (O.D.): Phone: (+33) 682272105. E-mail:

olivier.desrues@gmail.com 


\section{$1 \quad$ ABSTRACT}

2 The fate of condensed tannins (CTs) along the digestive tract of ruminants is not well

3 known and may account for the variable efficacy of CTs against gastrointestinal

4 nematodes in different locations. Here, we analyzed sainfoin CTs in the digesta of cattle

5 from two separate experiments. When using the acetone-butanol- $\mathrm{HCl}$ assay, the total CTs

6 concentrations in the digestive tract were close to those in the diets (6.3 and $1.5 \%$ of DM

7 in Expt. 1 and 2, resp.) indicating that CTs remained largely undegraded and unabsorbed.

8 Yet with the thiolysis assay in Expt. 1, CTs concentration was much higher in the

9 abomasum $(2.3 \pm 0.4 \%$ of DM) compared with the rumen, small and large intestines,

10 along with increases of mean size and percentage of prodelphinidins within CTs. This

11 corroborates the anthelmintic efficacy reported only against Ostertagia ostertagi in the

12 abomasum. In Expt. 2, no anthelmintic effect was observed against the larval

13 exsheathment in the rumen, probably because the dietary level of CTs was too low.

14 Overall, the level of CTs accessible to thiolysis in the gut appears to be critical for

15 anthelmintic activity, which is favored under the acidic conditions of the abomasum.

17 KEY-WORDS: proanthocyanidins; diet; helminth parasite; Ostertagia ostertagi; Cooperia oncophora; digesta; feces 


\section{INTRODUCTION}

The control of gastrointestinal nematodes in cattle still relies extensively on the use of anthelmintic drugs to reduce production losses and diseases. ${ }^{1}$ As farmers may have to face increasing numbers of drug-resistant nematode populations in cattle, ${ }^{2}$ the use of bioactive natural compounds with anthelmintic properties may help to achieve more sustainable parasite control. Research has focused on condensed tannins (CTs; syn. proanthocyanidins), especially those found in temperate forage legumes such as sainfoin (Onobrychis viciifolia), which is also recognized for its high feeding values. ${ }^{3}$

Belonging to the family of flavonoids (a group of polyphenols), CTs occur in plants as mixtures of flavan-3-ol polymers and are usually described by their mean degree of polymerization (mDP). In addition, each constitutive flavan-3-ol subunit can be characterized by the number of hydroxyl groups in both the A- and B-rings and the relative stereochemistry of the substituents on the C-ring (i.e. cis- (epi) or trans-configurations). Hence, the flavan-3-ols catechin and epicatechin have two $\mathrm{OH}$ groups adjacent to each other (on carbons 3 and 4) on the B-ring and give rise to procyanidins (PCs), while gallocatechin and epigallocatechin have three $\mathrm{OH}$ groups adjacent to each other (on carbons 3, 4 and 5) on the B-ring and give rise to prodelphinidins (PDs). The bioactivity of CTs, which is mostly explained by binding to other macromolecules, such as proteins, but also to polysaccharides and lipids, can be greatly influenced by various factors such as the structural diversity of CTs, solution conditions and protein characteristics. ${ }^{4}$ For instance, increases in tannin size (mDP) and PDs (molar percentage) have shown greater capacity to bind to proteins ${ }^{4}$ and exhibit higher in vitro anthelmintic activities. ${ }^{5-8}$ Moreover, CTs encounter a large variety of macromolecules and are subjected to various conditions (e.g. $\mathrm{pH}$, temperature) from plant harvest to digestion, which can 
determine the nature and strength of the interactions between CTs and proteins. In fact, plant processing such as drying, pelleting or ensiling have been shown to increase the fraction of protein-bound CTs ${ }^{9,10}$ or partly degrade CTs. ${ }^{11}$ Moreover, reversible interactions (non-covalent links) were proposed for the formation of CTs-protein complexes in the rumen at a favorable $\mathrm{pH}$ range of $5-7$, and dissociation in the acidic abomasum, which impedes CTs-protein complexation. ${ }^{12}$ Also, the recovery by butanol-HCl of CTs from Lotus corniculatus fed to sheep was low in the lower part of the digestive tract, ${ }^{13}$ probably due to irreversible interactions (covalent links) formed after the oxidization of polyphenols in such alkaline conditions ${ }^{12}$ or colonic fermentation. ${ }^{14}$

Studies in sheep have shown that CTs apparently are not absorbed. ${ }^{13,15}$ However, ruminant species may have different adaptations and tolerance to dietary CTs; secretion of tannin-binding salivary proteins appears to be a putative defense mechanism, ${ }^{16}$ and this complicates the comparison of CTs effects across animal species. In regard of the anthelmintic effects, CTs can be directly detrimental to the worms at various life stages. ${ }^{17}$ However, the anthelmintic activity of CTs may also vary according to the different hosts ${ }^{18}$ or gastrointestinal nematode species as shown in vitro. ${ }^{7,8,19}$ Additionally, these nematodes reside in different gut compartments, which may account for the reported variation in anthelmintic activity. In fact, a greater effect against abomasal nematode species compared with intestinal species has been noticed in feeding trials with sainfoin in sheep ${ }^{20,21}$ and cattle. ${ }^{22}$ However, no studies have directly linked CTs concentrations and structures along the gut with anthelmintic activity.

In this study, based on two separate experiments in which sainfoin was fed to cattle, we aimed at 1) analyzing the concentrations and structural compositions of CTs in the feed (dried pellets of cv. Perly in Expt. 1; silages of cv. Zeus and Esparcette in Expt. 2), the 
digesta (rumen, abomasum, small and large intestines in Expt. 1; rumen in Expt. 2) and in feces, and 2) linking the results with parasitological findings from the same experiments. In Expt. 1 an overall anthelmintic effect resulting in a significant reduction of Ostertagia ostertagi counts by $50 \%$ in the abomasum was observed while there was no effect against Cooperia oncophora in the small intestine of young cattle, as previously described in details. ${ }^{22}$ In Expt. 2 we studied the effect against the larval exsheathment in the rumen of fistulated cows.

To address this, we used two different analytical methods, namely, acetone-butanol- $\mathrm{HCl}$ and thiolysis, which depolymerize CTs without prior extraction and can provide complementary data. In fact, the acetone-butanol- $\mathrm{HCl}$ is a quantitative colorimetric assay that has been optimized for quantification of "total" CTs including free and bound CTs in fresh forages ${ }^{23}$ and tends to give a higher color yield than the traditional butanol- $\mathrm{HCl}$ reagent. The thiolysis is less sensitive to CTs in fermented samples (e.g. silage), where it mainly detects "free" CTs. ${ }^{24}$ In contrast to the acetone-butanol- $\mathrm{HCl}$ assay, thiolysis when coupled with HPLC-MS provides an insight into the structure of CTs in terms of subunits (flavan-3-ol) composition.

85

7

\section{MATERIALS AND METHODS}

\section{Chemicals}

Hydrochloric acid (36\%, analytical reagent grade), acetone (analytical reagent grade), butan-1-ol (analytical reagent grade), methanol (HPLC grade) and formic acid were purchased from ThermoFisher Scientific Ltd. (Loughborough, UK). Ammonium iron (III) sulphate dodecahydrate was from Acros Organics Ltd (Geel, Belgium). 


\section{Feeding Trial with Calves Infected with Gastrointestinal Nematodes (Expt. 1)}

This experiment was conducted in the fall 2013 at the Large Animal Facilities of University of Copenhagen, Tåstrup, Denmark, as a sub-project of a previous in vivo study of anthelmintic effects of dried pelleted sainfoin (third cut of pure-stand sainfoin cv. Perly) in cattle. ${ }^{22}$ Briefly, fifteen 2-4 month-old Jersey male calves were divided into two groups and fed isoproteic and isoenergetic diets comprising ryegrass-clover hay in addition to either a commercially available concentrate (55-65\% of the diet) [Group control (CO); $n=6$ ] or sainfoin pellets $(90 \%$ of the diet in average; increasing to $96 \%$ during the last two days of the experiment) [Group sainfoin (SF); $n=9$ ]. The animals in each group were penned in subgroups of three, according to bodyweights, to avoid bullying behavior and to better estimate the feed consumption. The feed intake of each subgroup was recorded daily. Then, the calves were infected with 10,000 third-stage larvae (L3) of O. ostertagi and 66,000 L3 of $C$. oncophora after 16 days of feed adaption. The calves were euthanized 42 days post infection for recovery of worms and digesta samples. Immediately after evisceration, $50 \mathrm{~mL}$ plastic tubes (or $15 \mathrm{~mL}$ for the organs containing worms) were filled with digesta from the rumen, whole abomasum (poured into a bucket and mixed), whole small intestine (poured into a bucket and mixed), large intestine and feces from each animal and stored at $-20^{\circ} \mathrm{C}$ until use. Worms were recovered from the abomasum and small intestine as previously described. ${ }^{22}$ Feed samples $(500 \mathrm{~g})$ were collected at the beginning of the study. The study was approved by the Animal Experiments Inspectorate, Ministry of Justice, Denmark (Ref. 2013-15-2934-00763). 


\section{Larval Exsheathment in the Rumen of Adult Cows (Expt. 2)}

The second experiment was conducted in the spring 2014 at the Carus Research Facilities of Wageningen University \& Research, The Netherlands. We assessed the effect of sainfoin silages on the exsheathment kinetics of infective third-stage larvae (L3) of $O$. ostertagi and $C$. oncophora in specially designed semi-permeable tubes placed into the rumen of fistulated cattle. Each test was performed between 0900 and $1200 \mathrm{~h}$ using three Holstein cows in late lactation or dry period and fitted with a rumen fistula. To prevent feed selection all diets were prepared as total mixed rations which were stored at $4{ }^{\circ} \mathrm{C}$ for $1-2$ days prior to use. The feed was offered ad libitum and replaced twice daily with a new batch (0800 and $1600 \mathrm{~h}$ ). First, we tested the larval exsheathment following feeding with a control diet (CT-free) containing grass silage, maize silage and concentrate. Secondly, we incorporated a mixture of sainfoin silages ( $80 \% \mathrm{cv}$. Zeus and $20 \% \mathrm{cv}$. Esparcette) which constituted $40 \%$ of the ration on DM basis for 3 days and performed another exsheathment test. Then, we increased the same mixture of sainfoin silages to $80 \%$ of the diet and performed L3 exsheathment tests after 1, 3 and 5 days. Sainfoin cultivars Zeus and Esparcette were separately grown, harvested (second cut) and ensiled as previously described. ${ }^{25}$

The L3 were obtained from feces cultured for 13 days at $20^{\circ} \mathrm{C}$, which were collected from donor calves mono infected with drug-susceptible isolates of 0 . ostertagi (ref label: OOSG10) and C. oncophora kindly provided by M. Fisher (Ridgeway Research Ltd., St Briavels, UK) and J. Demeler and G. von Samson-Himmelstjerna (Freie Universität Berlin, Germany), respectively. The batches of $\mathrm{L} 3$ were kept at $5^{\circ} \mathrm{C}$ for 3 and 6 months, respectively, prior to use. Ensheathment was confirmed before inoculation. Approximately 200 L3 of each species were pipetted into a separate small plastic tube $(3 \times 1 \mathrm{~cm})$ fitted 
with nylon mesh ( $10 \mu \mathrm{m}$ pore size) on both sides. The pore size corresponded to less than half of the width of $L 3$ of these nematode species, which ensured that the $L 3$ remained in the tube without perturbing the passage of rumen fluid. For each time point, one tube with L3 per nematode species was placed in a small nylon bag (40 $\mu \mathrm{m}$ pore size). The nylon bags were inserted in a net inside the rumen of each fistulated cow after $0,40,80,120$ and $160 \mathrm{~min}$. To retain the net in the rumen juice at the bottom of the organ the net was connected to the fistula at one end and to a stainless steel weight at the other end. All bags were retrieved simultaneously after the last time point. Then, 100 L3 from each tube were placed on a slide and the exsheathment process was stopped by addition of Lugol solution (Sigma-Aldrich Ltd., NL). The L3 were observed under a microscope $(\times 100)$ and counted as exsheathed when the larval sheath was broken or lost.

Moreover, $\mathrm{pH}$ and temperature of the rumen were recorded with a probe during all exsheathment tests. The $\mathrm{pH}$-meter was calibrated each day prior to the test, using two calibration points: $\mathrm{pH} 7.0$ and 4.0. Finally, we collected samples from four different places in the ventral and dorsal rumen sac, feces and all feed items on the last day of the trial and kept them at $-20{ }^{\circ} \mathrm{C}$ until use. This experiment was approved by the Institutional Animal Care and Use Committee of Wageningen University \& Research and executed in accordance with EU directive 2010/63/EU implemented by the Dutch legislation on the use of experimental animals.

\section{Sample Preparation and CTs Analysis by Acetone-Butanol-HCl and Thiolysis}

\section{Assays}

The frozen samples of feed (only silage), digesta and feces were freeze-dried and all samples were ground $(<1 \mathrm{~mm})$. Then, the total CTs concentrations were analyzed using 
the acetone-butanol- $\mathrm{HCl}$ method ${ }^{23}$ with slight modifications as previously described..$^{25}$ Briefly, $10 \mathrm{mg}$ of ground material was added in a glass tube in triplicate for every sample. To each tube, $10 \mathrm{~mL}$ of reagent was added, which contained $150 \mathrm{mg}$ of ammonium iron (III) sulphate dodecahydrate, $3.3 \mathrm{~mL}$ of water, $5 \mathrm{~mL}$ of $12 \mathrm{M} \mathrm{HCl}, 42 \mathrm{~mL}$ of butan-1-ol and $50 \mathrm{~mL}$ acetone. The tubes were left for $1 \mathrm{~h}$ at room temperature and then heated at $70^{\circ} \mathrm{C}$ for $2.5 \mathrm{~h}$ in the dark. The samples were then analyzed by spectrophotometry (V530 Spectrophotometer, Jasco, Dunmow, UK) by scanning between 450-650 nm. Purified CTs fraction of freeze-dried sainfoin was used for CTs calibration [CTs content $=100 \%$, assessed by liquid chromatography-mass spectrometry (LC-MS) after thiolysis]. In addition, in situ thiolysis was performed in duplicate according to Gea et al. ${ }^{26}$ with slight modifications. In short, $200 \mathrm{mg}$ of ground material was weighed into a screw-top glass tube and a reagent containing $2 \mathrm{~mL}$ of $\mathrm{MeOH}, 1 \mathrm{~mL}$ of $3.3 \% \mathrm{HCl}$ in $\mathrm{MeOH}$ and $100 \mu \mathrm{L}$ of benzyl mercaptan $(B M)$ was added. The tubes were heated at $40^{\circ} \mathrm{C}$ for $1 \mathrm{~h}$ under vigorous stirring. Then, $9 \mathrm{~mL}$ of $1 \%$ formic acid in water was added and the tubes were subsequently vortex mixed and centrifuged for $5 \mathrm{~min}$ before transfer to high performance liquid chromatography (HPLC) vials. The CTs analysis by HPLC and LC-MS was described in detail by Williams et al. ${ }^{6}$ with taxifolin as an external standard. This provided data on the molar percentages of the different flavan-3-ol subunits of the CTs in terms of terminal and extension (BM-adduct) units. The results provide information on CTs concentration ( $\mathrm{g} / 100 \mathrm{~g}$ dry matter), mean degree of polymerization (mDP), and molar percentages of PCs vs. PDs and cis- vs. trans flavan-ols subunits. ${ }^{26,27}$ 


\section{Statistical Analysis}

The statistical analyses were performed with R software (version 3.2). In Expt. 1, the replicated CTs concentrations were averaged for each sample. Thus, the mean CTs concentrations of digesta and feces of sainfoin fed calves (=experimental units), as analyzed by the acetone-butanol- $\mathrm{HCl}$ assay ( $\mathrm{n}=9$ calves) or thiolysis ( $\mathrm{n}=8$ calves), were compared using pairwise comparisons with Wilcoxon rank sum tests including sample type (rumen, abomasum, small intestine, large intestine and feces) and post-hoc Holm's test for multiple comparisons. The results for CTs structures were not subjected to statistical analysis due to low recovery of CTs in the small and large intestines. In Expt. 2, the effects of sainfoin on the larval exsheathment were analyzed with linear regression models run separately for each parasite species and included: response variable (\% of exsheathed larvae in triplicates) and explanatory factors as fixed effects (diet and time point). The values of rumen $\mathrm{pH}$ and temperature were compared between diets by one-way ANOVA with Tukey post-hoc test. Effects were considered significant at $\mathrm{P}<0.05$.

\section{RESULTS \& DISCUSSION}

\section{Analysis of "Total" CTs in Feed and Digesta/Feces by Acetone-Butanol-HCl Assay}

In Expt. 1, the total CTs concentration in the sainfoin pellets was $6.5 \pm 0.2 \%$ of dry matter (DM) using the acetone-butanol-HCl method (Figure 1), corresponding to a dietary level of $6.3 \pm 0.0 \%$ of DM after correction for a small proportion of feed without CTs. In calves of Group SF, CTs concentrations in digesta samples were lower in the rumen (mean\% of DM $\pm S D ; 3.0 \pm 1.4 ; P<0.05)$ and increased gradually along the digestive tract. The average values of CTs concentrations in the abomasum $(5.8 \pm 0.6 \%$ of DM), small intestine $(6.2 \pm$ $0.9 \%$ of $\mathrm{DM})$ and large intestine $(6.6 \pm 1.1 \%$ of $\mathrm{DM})$ were close to that found in the pellets, 
and maximum values were found in feces $(7.8 \pm 1.4 \%$ of DM). No CTs were detected in any control feed or control digesta. In Expt. 2, CTs concentrations in sainfoin silages were low: $1.8 \pm 0.05 \%$ and $2.5 \pm 0.09 \%$ of DM for cv. Zeus and Esparcette, respectively. Thus, the dietary level of CTs was estimated to be $1.5 \pm 0.0 \%$ of DM when the mixture of sainfoin silages constituted $80 \%$ of the ration. The CTs concentrations of rumen digesta or fecal samples from the 3 cows were on average $1.2 \pm 0.3$ and $1.8 \pm 0.1 \%$ of DM, respectively, on day 5 with $80 \%$ sainfoin in the diet. Moreover, the increase in CTs concentration of the rumen and the feces was consistent for all animals.

Thus, the total CTs concentration was highest in the feces in both experiments. This was expected; while organic matter is digested in the intestinal tract, uncertainty remains regarding the extent to which CTs concentrations and compositions are affected in the gut of the different ruminant species. ${ }^{28}$ The harsh reaction conditions in acetone-butanol- $\mathrm{HCl}$ $\left(70{ }^{\circ} \mathrm{C}, 5 \% \mathrm{HCl}, 2.5 \mathrm{~h}\right)$ are more likely to release free and most of the bound CTs from feed and digesta matrices. However, when we consider a realistic DM digestibility of $60 \%$, we found that the average concentrations of CTs in feces should have been twofold higher in both experiments; therefore a large proportion of CTs was not accounted for in the current study with young and adult cattle. Possible reasons for CTs losses are microbial fermentation that lead to depolymerization into bioavailable oligomers or biotransformation. ${ }^{14,29}$ These intestinal losses agree with reported CTs losses during silage fermentation. ${ }^{24}$ In addition, CTs may be involved in reactions with digesta components that lead to covalent links at acid and alkaline $\mathrm{pH}$ values, ${ }^{30}$ and these derivative products may not be detected by current analytical methods. Finally, there was no evident relationship between total CTs concentrations in the different gut compartments measured with the 
acetone-butanol- $\mathrm{HCl}$ assay and anthelmintic activity against nematodes in these two separate experiments.

\section{Analysis of "Free" CTs in Feed and Digesta/Feces in Expt. 1 by Thiolysis and LC-MS} as Indicator of Anthelmintic Activity.

In this study, we have clearly established a relationship between the concentrations and compositions of "free" CTs, when using the thiolysis method, in various compartments of the gastrointestinal tract and anthelmintic activity against gastrointestinal nematodes in cattle fed with sainfoin.

Overall, CTs concentrations obtained by thiolysis were lower than those obtained by the acetone-butanol-HCl method and with a different pattern of CTs changes between gut compartments (Figure 1 and 2.A). In fact, CTs concentrations obtained by thiolysis (Figure 2.A) were much higher in sainfoin pellets $(2.0 \pm 0.0 \%$ of DM) and abomasum $(2.3 \pm 0.4 \%$ of DM) compared with other compartments. In contrast, mean levels in rumen and feces were below $0.5 \%$, and CTs were only detected in the small intestine of four animals and in the large intestine of three. The higher level of assayable CTs in the abomasum is in accordance with the significantly higher anti-parasitic activity of this diet comprising mainly of sainfoin pellets against 0 . ostertagi compared to the control (mean worm burden $\pm \mathrm{SD}$ : $1,331 \pm 947$ in Group SF versus 2,715 \pm 894 in Group CO; P<0.05). ${ }^{22}$ Conversely, the almost complete lack of CTs measured by thiolysis in the small intestine is linked to the lack of efficacy of sainfoin against $C$. oncophora (mean worm burden \pm SD: 19,664 \pm 22,496 in Group SF versus 22,447 $\pm 17,639$ in Group CO; NS). ${ }^{22}$ These findings support previous feeding trials with sainfoin in small ruminants, where $H$. contortus, residing in the abomasum, was generally more affected than intestinal species, e.g. Cooperia curticei and 
Trichostrongylus colubriformis. ${ }^{20,21}$ The conditions in the gut can vary from $\mathrm{pH}<3$ to 8 and appear to impact on the reactivity and thus recovery of "free" CTs after thiolysis (mild reaction conditions; $40^{\circ} \mathrm{C}, 1.1 \% \mathrm{HCl}, 1 \mathrm{~h}$ ). Thus, sainfoin $\mathrm{CTs}$ seemed to be bound to the digesta matrix of the rumen and released from these CTs-macromolecule complexes in the abomasum, which agrees with sainfoin CTs-protein complexes being stable only between $\mathrm{pH} 3.5-7.0 .^{12}$ In the lower parts of the digestive tract, the presence of tightly bound CTs could originate from irreversible reactions between CTs and feed matrix components, digestive enzymes or gut microbes that lead to thiolysis-resistant complexes at alkaline $\mathrm{pH}$; more work is needed to identify these reaction products. ${ }^{24}$ This study has highlighted the difficulty of analyzing CTs in digested and fermented samples and the results should be interpreted with caution as the number of CTs-containing samples was limited for the small and large intestines. It is of interest that the inflamed conditions in the abomasum of animal \#4413, perhaps inducing a higher $\mathrm{pH}$, resulted in noticeably different CTs results, e.g. values in the abomasum were more than five SD away from the group mean and considered as outliers (Figure 2). This inflammation was likely related to the infection, edematous abomasitis as reported by Uzal et al. ${ }^{31}$ and apparently happened at a late stage of the study as no clinical signs were observed.

Further, the CTs compositional analysis showed highest levels of mDP and PDs in the sainfoin pellets $(\mathrm{mDP}=11.1 \pm 0.2$ and $\mathrm{PDs}=81.3 \pm 0.2 \%)$ and the abomasum $(\mathrm{mDP}=15.9 \pm$ 1.0 and PDs $=86.6 \pm 0.5 \%$ ). In all samples the molar percentages of cis flavan-3-ols were within $74-85 \%$ (Figure 2.B-D). It can be seen that especially the larger PD-rich tannins were released in the abomasum; and this is interesting because these tannin types tend to be more difficult to extract. ${ }^{24}$ In addition, the binding affinity of CTs towards macromolecules is also positively correlated with $\mathrm{mDP}$ and PDs $\%,{ }^{4}$ thus confirming that 
larger and PD-rich CTs were preferably bound in the rumen and released in the abomasum (Figure 2.C-D). It is notable that $\mathrm{mDP}$ and PDs\% are positively correlated within sainfoin CTs. ${ }^{5}$ An increase of these two structural parameters, as we observed in the abomasum, has been linked to greater in vitro anthelmintic activity of CTs against cattle nematodes. ${ }^{5,8}$ Moreover, sainfoin CTs contain complex mixtures of flavan-3-ols, ${ }^{32}$ as illustrated by our findings, where all types of flavan-3-ol subunits were detected in extension and terminal units in sainfoin pellets and most digesta/fecal samples (Figure 3). Although the CTs composition can vary between different sainfoin accessions, ${ }^{26}$ epigallocatechin extension units tend to be the major flavan-3-ol unit in sainfoin CT. ${ }^{24,33}$ This was also evident in our sainfoin pellets and the samples from the abomasum (Figure 3.B). A greater anthelmintic activity of epigallocatechin as compared with catechin or epicatechin was shown recently against cattle nematodes. ${ }^{8}$ The importance of the CTs composition on anthelmintic activity is now well recognized and was also highlighted in studies with the warm season legume Lespedeza cuneata, which is particularly rich in large PD-type CTs. ${ }^{9,34}$ CTs have been shown to survive the acidic conditions of the human stomach ${ }^{14}$ and the present study found high mDP values for CTs in the abomasum. The analytical techniques cannot provide information on whether some of the CTs were acid cleaved in this organ, i.e. $\mathrm{pH}$ around 2 in the abomasum of parasite-free cattle. ${ }^{35}$ The exact mechanisms for the anthelmintic efficacy of the easily assayable CTs, i.e. not tightly bound $\mathrm{CTs},{ }^{24}$ in the abomasum remain to be uncovered. Most likely the acidic environment of the abomasum facilitates the release of tightly bound CTs from complexes within the digesta matrix and this enables better interactions with both the thiolysis reagent and nematode proteins. ${ }^{17}$ Indeed, Jones and Mangan ${ }^{12}$ reported that the CTs-Rubisco protein complex is unstable at $\mathrm{pH} \leq 3$ and, therefore, the abomasal conditions may allow 
the CTs to exhibit their anthelmintic effects more readily. It is also of interest that heavy infections with abomasal nematodes are associated with higher $\mathrm{pH}$ values, which could in turn lower CTs activity. However, there are several factors that may influence the efficacy of CTs: i) the nematode cuticle is rich in collagen in particular at the adult stage,$^{36}$ and contains a high proportion of proline residues that favor interactions with CTs; ii) CTs are known to interact most strongly close to the isoelectric point of proteins, ${ }^{37}$ which may differ between proteins from feeds, animals, and worms; iii) $O$. ostertagi adults are actively feeding and reside mainly in the mucus layer of the abomasum, thus, the reactivity of CTs may differ in the local micro-environment of the mucosa and the worm. It seems reasonable to assume that in our study (Expt. 1) abomasal pH was close to normal at the end of the trial, considering the low infection levels and the timing. In fact, the rise of abomasal $\mathrm{pH}$ seems to correspond with the emergence of nematodes from gastric glands, which can vary between nematode species, e.g. elevated pH was observed 20 days post infection with $O$.ostertagi in calves. ${ }^{38}$ Although $\mathrm{pH}$ can reach neutral values in some cases ${ }^{38}$ the severity of such changes is likely related to the parasite load and will be transient. As an example, studies in sheep infected with $O$. circumcincta demonstrated that $\mathrm{pH}$ returns to normal within 25-30 days post infection. ${ }^{39} \mathrm{It}$ has also been suggested that this elevation of $\mathrm{pH}$ is directly induced by parasites through the release of chemicals, to increase their survival as they do not usually survive in acidic medium. ${ }^{40}$ Despite the profound effect on worm numbers, the adult worms from the calves fed sainfoin in Expt. 1 showed only minor morphological changes (i.e. few aggregates and damage) by scanning electron microscopy as compared with worms isolated from calves fed a control diet. ${ }^{22}$ In contrast, other in vivo studies with sainfoin ${ }^{41}$ and Lespedeza cuneata ${ }^{34}$ have reported pronounced damage of adult $H$. contortus (especially female worms). It is noteworthy that 
the abomasum of the youngest calf, harboring the highest number of abomasal worms, ${ }^{22}$ had a higher water concentration. This resulted in a much lower CTs concentration in the abomasum (g CTs/kg of wet digesta) with both analytical methods, whereas CTs concentration in DM varied only slightly.

\section{Analysis of "free" CTs in Expt. 2 by Thiolysis and LC-MS and Kinetics of Larval}

\section{Exsheathment in the Rumen}

In accordance with the results of Expt. 1, the CTs concentrations were much lower when using the thiolysis method, i.e. $0.02 \pm 0.0$ and $0.67 \pm 0.0 \%$ of $\mathrm{DM}$ for sainfoin silages of cv. Zeus and Esparcette, respectively. Processing such as pelleting ${ }^{9}$ or ensiling ${ }^{10}$ has shown to increase the percentage of bound CTs and this could explain the low recovery of CTs with thiolysis in sainfoin samples for both studies. However, we could only detect PC-type tannins in silage of cv. Zeus that was the main component of the diet, which were based on epicatechin as terminal and extension units with mDP of $4.0 \pm 0.5$. For silage of cv. Esparcette, measured terminal units were only of catechin and extension units were of all types but mainly epigallocatechin and epicatechin (summarized as PC\%= $37 \pm 0.1$; cis $\%=88 \pm 0.2 ; \mathrm{mDP}=34 \pm 1.9)$. These tannin features were also reflected in the rumen/fecal samples from the last day of the experiment, although with a large variation and low CTs concentrations $(0.09 \pm 0.06$ and $0.14 \pm 0.16 \%$ of $\mathrm{DM}$ in rumen and feces, respectively). Thus, PC-type tannins were found predominantly in the rumen and feces (70 \pm 26 and $73 \pm 31 \%$ of CTs, respectively), these PCs had cis-configuration ( $83 \pm 12$ and 84 $\pm 11 \%$ of CTs, respectively) and an mDP of $5.1 \pm 1.7$ and $6.6 \pm 5.4$, respectively. Moreover, terminal units were only of the PC-type (catechin and epicatechin) and 
extension units were predominantly epigallocatechin and epicatechin in rumen and fecal samples.

The exsheathment for 0 . ostertagi L3 occurred very rapidly, with $90-100 \%$ of the L3 exsheathed after 80 min of incubation in the rumen with the control diet (Figure 4.A), in accordance with a previous study. ${ }^{42}$ We have also confirmed in vivo that L3 exsheathment of the intestinal species $C$. oncophora is triggered in the rumen of cattle, in a similar manner as $O$. ostertagi. Although nematode species are usually thought to exsheath in the organ just prior to the living site of the adult stage, Cooperia spp. seem to be an exception. This was shown in vitro and in vivo for $C$. curticei in sheep, ${ }^{43,44}$ and in vitro for $C$. oncophora by using rumen digesta of sheep. ${ }^{44}$ The inclusion of sainfoin silages even at the highest level did not reduce the rate of larval exsheathment. Yet, the potency of CTscontaining sainfoin silages on the larval exsheathment could not be conclusively evaluated as the dietary level of CTs was apparently too low, i.e. $1.5 \% \mathrm{DM}$ in the diet by the acetonebutanol- $\mathrm{HCl}$ method and thiolysis only detected a marginal level of CTs. ${ }^{45} \mathrm{~A}$ doseresponse effect in the exsheathment of $H$. contortus L3 was demonstrated in cannulated sheep with fresh sainfoin containing $3.9 \%$ of CTs. At a concentration of $75-100 \%$ of sainfoin in the diet a significant exsheathment delay was shown, whereas $25 \%$ dietary sainfoin did not generate this effect. ${ }^{46}$ To a lesser extent, other factors may also explain some of the differences between our study and this previous study, ${ }^{46}$ e.g. lower accessibility of CTs in silage than in fresh sainfoin, different CTs structures due to sainfoin accession, higher ruminal $\mathrm{pH}$, and shorter length of CTs exposure. Furthermore, compared to the control, the inclusion of sainfoin silage in our study resulted in a slightly faster exsheathment of L3, which was significantly faster for $C$. oncophora when sainfoin was included in the diet at a level of $80 \%$ for 3 or 5 days $(P<0.05)$. This was likely due to 
different local conditions in the rumen caused by the various diets, and possibly unrelated to the presence of CTs. Thus, the rumen temperature was found slightly higher at the beginning of the experiment with the control diet (mean temperature $\left({ }^{\circ} \mathrm{C}\right) \pm \mathrm{SD}: 41.4 \pm 0.3$ ) and gradually decreased following the inclusion of sainfoin silage in the diet: $40.7 \pm 0.3$ at $40 \%(P<0.1) ;$ and $40.1 \pm 0.3,40.4 \pm 0.1$ and $40.1 \pm 0.3$ at $80 \%$ on day 1,3 and 5 , respectively $(\mathrm{P}<0.05)$. More importantly, $\mathrm{pH}$ values in the rumen gradually increased with the inclusion of sainfoin in the diet, although this was not statistically significant $(P>0.05)$ and only measured once per trial. The mean $\mathrm{pH}$ values were: $6.25 \pm 0.04$ with the control diet; $6.34 \pm 0.23$ with $40 \%$ sainfoin silage in diet; and $6.55 \pm 0.32,6.66 \pm 0.25,6.69 \pm 0.09$ with $80 \%$ sainfoin silage in the diet for 1,3 and 5 days, respectively. We know that different physiological conditions in the rumen are likely to influence the rate of the host signal needed for the initiation of exsheathment. ${ }^{47}$ For example, a CT-free diet, which drastically reduced ruminal $\mathrm{pH}$, was shown to delay significantly the larval exsheathment of 0. ostertagi L3 in vivo, ${ }^{42}$ and $C$. curticei could exsheath faster in vitro at $\mathrm{pH} 7-8.43$ The present study suggests that a certain dietary level of active CTs from sainfoin, as indicated with the thiolysis method, is essential for an anthelmintic effect in the first place. Although CTs seem to be mainly undegraded and unabsorbed in the digestive tract of cattle as shown with the acetone-butanol-HCl assay, the gut conditions appeared to influence the reactivity of CTs and therefore the anthelmintic activity. In conclusion, the low recoveries of CTs by thiolysis in the rumen and small intestine were associated with a lack of efficacy against the larval exsheathment and the worm burdens of adult $C$. oncophora, respectively. However, the apparent release of active CTs from sainfoin in the abomasum led to a significant reduction in worm burdens of adult $O$. ostertagi. 
400

401

402

403

404

405

406

407

408

409 final manuscript.

\section{ABBREVIATIONS USED}

CTs - condensed tannins; HPLC - high performance liquid chromatography; L3 - thirdstage larvae; mDP - mean degree of polymerization; MS - mass spectrometry; NS - non significant; PCs - procyanidins; PDs - prodelphinidins; SD - standard deviation

\section{AUTHOR CONTRIBUTIONS}

OD, WFP, HLE and SMT designed the animal experiments. OD, SMT and IMH designed the chemical analyses. OD carried out the study and analyzed the data. OD wrote the manuscript with inputs from all the co-authors. All authors critically read and approved the final manuscript.

\section{ACKNOWLEDGMENTS}

412 Authors are grateful to the people from our group and Carus Research facilities who 413 helped with the animals and sampling, and Mr. C. Drake from Reading University for 414 teaching of tannin analysis. Sainfoin pellets in Expt. 1 were kindly provided by

415 Multifolia/MG2MIX (Viâpres-le-Petit, France) Ltd.

417 NOTES

418 The authors declare no competing financial interest. 
421 (1) Charlier, J.; van der Voort, M.; Kenyon, F.; Skuce, P.; Vercruysse, J., Chasing helminths and their economic impact on farmed ruminants. Trends Parasitol. 2014, 30, $423 \quad 361-367$.

424

(2) Sutherland, I. A.; Leathwick, D. M., Anthelmintic resistance in nematode parasites of 425 cattle: a global issue? Trends in Parasitol. 2011, 27, 176-181.

(3) Hoste, H.; Torres-Acosta, J. F. J.; Sandoval-Castro, C. A.; Mueller-Harvey, I.; Sotiraki,

S.; Louvandini, H.; Thamsborg, S. M.; Terrill, T. H., Tannin containing legumes as a model for nutraceuticals against digestive parasites in livestock. Vet. Parasitol. 2015, 212, 5-17. (4) Le Bourvellec, C.; Renard, C. M. G. C., Interactions between polyphenols and macromolecules: quantification methods and mechanisms. Crit. Rev. Food Sci. 2011, 52, 213-248.

(5) Novobilský, A.; Stringano, E.; Hayot Carbonero, C.; Smith, L. M. J.; Enemark, H. L.; Mueller-Harvey, I.; Thamsborg, S. M., In vitro effects of extracts and purified tannins of sainfoin (Onobrychis viciifolia) against two cattle nematodes. Vet. Parasitol. 2013, 196, 532-537.

(6) Williams, A.; Fryganas, C.; Ramsay, A.; Mueller-Harvey, I.; Thamsborg, S., Direct anthelmintic effects of condensed tannins from diverse plant sources against Ascaris suum. PloS One 2014, 9, e97053.

(7) Quijada, J.; Fryganas, C.; Ropiak, H. M.; Ramsay, A.; Mueller-Harvey, I.; Hoste, H.,

Anthelmintic activities against Haemonchus contortus or Trichostrongylus colubriformis from small ruminants are influenced by structural features of condensed tannins. J. Agric. Food Chem. 2015, 63, 6346-6354. 
443

444

445

446

447

448

449

450

451

452

453

454

455

456

457

458

459

460

461

462

463

464

465

(8) Desrues, O.; Fryganas, C.; Ropiak, H. M.; Mueller-Harvey, I.; Enemark, H. I.;

Thamsborg, S. M., Impact of chemical structure of flavanol monomers and condensed tannins on in vitro anthelmintic activity against bovine nematodes. Parasitology 2016, 143, 444-454.

(9) Terrill, T. H.; Mosjidis, J. A.; Moore, D. A.; Shaik, S. A.; Miller, J. E.; Burke, J. M.; Muir, J. P.; Wolfe, R., Effect of pelleting on efficacy of sericea lespedeza hay as a natural dewormer in goats. Vet. Parasitol. 2007, 146, 117-122.

(10) Minnée, E. M. K.; Woodward, S. L.; Waghorn, G. C.; Laboyrie, P. G., The effect of ensiling forage legumes on condensed tannins. Agron. N. Z. 2002, 32, 117-119.

(11) Gaugler, M.; Grigsby, W. J., Thermal Degradation of Condensed Tannins from Radiata Pine Bark. J. Wood Chem. Technol. 2009, 29, 305-321.

(12) Jones, W. T.; Mangan, J. L., Complexes of the condensed tannins of sainfoin (Onobrychis viciifolia scop.) with fraction 1 leaf protein and with submaxillary mucoprotein, and their reversal by polyethylene glycol and pH. J. Sci. Food Agric. 1977, 28, 126-136. (13) Terrill, T. H.; Waghorn, G. C.; Woolley, D. J.; McNabb, W. C.; Barry, T. N., Assay and digestion of C-labelled condensed tannins in the gastrointestinal tract of sheep. Brit. J. Nutr. 1994, 72, 467-477.

(14) Mena, P.; Calani, L.; Bruni, R.; Del Rio, D., Chapter 6 - Bioactivation of highmolecular-weight polyphenols by the gut microbiome. In Diet-Microbe Interactions in the Gut, Rio, K. T. D., Ed. Academic Press: San Diego, 2015; pp 73-101.

(15) López-Andrés, P.; Luciano, G.; Vasta, V.; Gibson, T. M.; Biondi, L.; Priolo, A.; MuellerHarvey, I., Dietary quebracho tannins are not absorbed, but increase the antioxidant capacity of liver and plasma in sheep. Brit. J. Nutr. 2013, 110, 632-639. 
(16) Lamy, E.; Rawel, H.; Schweigert, F. J.; Capela e Silva, F.; Ferreira, A.; Costa, A. R.; Antunes, C.; Almeida, A. M.; Coelho, A. V.; Sales-Baptista, E., The effect of tannins on Mediterranean ruminant ingestive behavior: the role of the oral cavity. Molecules 2011, 16, 2766.

(17) Hoste, H.; Martinez-Ortiz-De-Montellano, C.; Manolaraki, F.; Brunet, S.; Ojeda-

Robertos, N.; Fourquaux, I.; Torres-Acosta, J. F. J.; Sandoval-Castro, C. A., Direct and indirect effects of bioactive tannin-rich tropical and temperate legumes against nematode infections. Vet. Parasitol. 2012, 186, 18-27.

(18) Max, R. A.; Kassuku, A. A.; Kimambo, A. E.; Mtenga, L. A.; Wakelin, D.; Buttery, P. J., The effect of wattle tannin drenches on gastrointestinal nematodes of tropical sheep and goats during experimental and natural infections. J. Agric. Sci. 2009, 147, 211-218.

(19) Molan, A. L., Effect of purified condensed tannins from pine bark on larval motility, egg hatching and larval development of Teladorsagia circumcincta and Trichostrongylus colubriformis (Nematoda: Trichostrongylidae). Folia Parasit. 2014, 61, 371-376. (20) Heckendorn, F.; Häring, D. A.; Maurer, V.; Zinsstag, J.; Langhans, W.; Hertzberg, H., Effect of sainfoin (Onobrychis viciifolia) silage and hay on established populations of Haemonchus contortus and Cooperia curticei in lambs. Vet. Parasitol. 2006, 142, 293300.

(21) Arroyo-Lopez, C.; Manolaraki, F.; Saratsis, A.; Saratsi, K.; Stefanakis, A.; Skampardonis, V.; Voutzourakis, N.; Hoste, H.; Sotiraki, S., Anthelmintic effect of carob pods and sainfoin hay when fed to lambs after experimental trickle infections with Haemonchus contortus and Trichostrongylus colubriformis. Parasite 2014, 21, 71. 
488 (22) Desrues, O.; Peña-Espinoza, M.; Hansen, T. V. A.; Enemark, H. L.; Thamsborg, S. 489 M., Anti-parasitic activity of pelleted sainfoin (Onobrychis viciifolia) against Ostertagia 490 ostertagi and Cooperia oncophora in calves. Parasites Vectors 2016, 9, 1-10.

491 (23) Grabber, J. H.; Zeller, W. E.; Mueller-Harvey, I., Acetone enhances the direct analysis 492 of procyanidin- and prodelphinidin-based condensed tannins in Lotus species by the 493 butanol-HCl-iron assay. J. Agric. Food Chem. 2013, 61, 2669-2678.

494 (24) Ramsay, A.; Drake, C.; Grosse Brinkhaus, A.; Girard, M.; Copani, G.; Dohme-Meier, 495 F.; Bee, G.; Niderkorn, V.; Mueller-Harvey, I., Sodium hydroxide enhances extractability 496 and analysis of proanthocyanidins in ensiled sainfoin (Onobrychis viciifolia). J. Agric. Food 497 Chem. 2015, 63, 9471-9479.

498 (25) Huyen, N. T.; Desrues, O.; Alferink, S. J. J.; Zandstra, T.; Verstegen, M. W. A.; 499 Hendriks, W. H.; Pellikaan, W. F., Inclusion of sainfoin (Onobrychis viciifolia) silage in dairy 500 cow rations affects nutrient digestibility, nitrogen utilization, energy balance, and methane 501 emissions. J. Dairy Sci. 2016, 99, 3566-3577.

502 (26) Gea, A.; Stringano, E.; Brown, R. H.; Mueller-Harvey, I., In situ analysis and structural 503 elucidation of sainfoin (Onobrychis viciifolia) tannins for high-throughput germplasm 504 screening. J. Agric. Food Chem. 2011, 59, 495-503.

505 (27) Ropiak, H. M.; Ramsay, A.; Mueller-Harvey, I., Condensed tannins in extracts from 506 European medicinal plants and herbal products. J. Pharm. Biomed. Anal. 2016, 121, 225507231.

508 (28) Mueller-Harvey, I., Unravelling the conundrum of tannins in animal nutrition and 509 health. J. Sci. Food Agric. 2006, 86, 2010-2037.

510 (29) Li, M.; Hagerman, A. E., Interactions between plasma proteins and naturally occurring 511 polyphenols. Curr. Drug Metab. 2013, 14, 432-445. 
512 513

514 515

(30) Hagerman, A. E., Fifty years of polyphenol-protein complexes. Recent Adv. Polyphenol Res. 2012, 3, 71-97.

(31) Uzal, F. A.; Plattner, B. L.; Hostetter, J. M., Chapter 1 - Alimentary System A2 Maxie, M. Grant. In Jubb, Kennedy \& Palmer's Pathology of Domestic Animals: Volume 2 (Sixth Edition), W.B. Saunders: 2016; pp 1-257.e2.

(32) Stringano, E.; Cramer, R.; Hayes, W.; Smith, C.; Gibson, T.; Mueller-Harvey, I., Deciphering the complexity of sainfoin (Onobrychis viciifolia) proanthocyanidins by MALDITOF mass spectrometry with a judicious choice of isotope patterns and matrixes. Anal. Chem. 2011, 83, 4147-4153.

(33) Malisch, C. S.; Lüscher, A.; Baert, N.; Engström, M. T.; Studer, B.; Fryganas, C.; Suter, D.; Mueller-Harvey, I.; Salminen, J.-P., Large variability of proanthocyanidin content and composition in sainfoin (Onobrychis viciifolia). J. Agric. Food Chem. 2015, 63, 10234 10242.

(34) Kommuru, D. S.; Whitley, N. C.; Miller, J. E.; Mosjidis, J. A.; Burke, J. M.; Gujja, S.; Mechineni, A.; Terrill, T. H., Effect of sericea lespedeza leaf meal pellets on adult female Haemonchus contortus in goats. Vet. Parasitol. 2015, 207, 170-175.

(35) Van Winden, S. C. L.; Müller, K. E.; Kuiper, R.; Noordhuizen, J. P. T. M., Studies on the $\mathrm{pH}$ value of abomasal contents in dairy cows during the first 3 weeks after calving. $J$. Vet. Med., A 2002, 49, 157-160.

(36) Fetterer, R., The cuticular proteins from free-living and parasitic stages of Haemonchus contortus-I. Isolation and partial characterization. Comp. Biochem. Physiol., Part B: Biochem. 1989, 94, 383-388.

(37) Hagerman, A. E.; Butler, L. G., The specificity of proanthocyanidin-protein interactions. J. Biol. Chem. 1981, 256, 4494-4497. 
(38) Jennings, F. W.; Armour, J.; Lawson, D. D.; Roberts, R., Experimental Ostertagia ostertagi infections in calves: studies with abomasal cannulas. Am. J. Vet. Res. 1966, 27, $1249-1257$.

(39) Lawton, D. E. B.; Reynolds, G. W.; Hodgkinson, S. M.; Pomroy, W. E.; Simpson, H. V., Infection of sheep with adult and larval Ostertagia circumcincta: Effects on abomasal pH and serum gastrin and pepsinogen. Int. J. Parasitol. 1996, 26, 1063-1074.

(40) Eiler, H.; Baber, W.; Lyke, W. A.; Scholtens, R., Inhibition of gastric hydrochloric acid secretions in the rat given Ostertagia ostertagi (a gastric parasite of cattle) extract. Am. J. Vet. Res. 1981, 42, 498-502.

(41) Martínez-Ortíz-de-Montellano, C.; Arroyo-López, C.; Fourquaux, I.; Torres-Acosta, J. F. J.; Sandoval-Castro, C. A.; Hoste, H., Scanning electron microscopy of Haemonchus contortus exposed to tannin-rich plants under in vivo and in vitro conditions. Exp. Parasitol. 2013, 133, 281-286.

(42) DeRosa, A. A.; Chirgwin, S. R.; Fletcher, J.; Williams, J. C.; Klei, T. R., Exsheathment of Ostertagia ostertagi infective larvae following exposure to bovine rumen contents derived from low and high roughage diets. Vet. Parasitol. 2005, 129, 77-81.

(43) Ahluwalia, J. S.; Charleston, W. A. G., Exsheathment of infective larvae of Cooperia curticei. N. Z. Vet. J. 1974, 22, 237-238.

(44) Hertzberg, H.; Huwyler, U.; Kohler, L.; Rehbein, S.; Wanner, M., Kinetics of exsheathment of infective ovine and bovine strongylid larvae in vivo and in vitro. Parasitology 2002, 125, 65-70.

(45) Hoste, H.; Jackson, F.; Athanasiadou, S.; Thamsborg, S. M.; Hoskin, S. O., The effects of tannin-rich plants on parasitic nematodes in ruminants. Trends Parasitol. 2006, 22, 253-261. 
560 (46) Brunet, S.; Aufrere, J.; El Babili, F.; Fouraste, I.; Hoste, H., The kinetics of 561 exsheathment of infective nematode larvae is disturbed in the presence of a tannin-rich 562 plant extract (sainfoin) both in vitro and in vivo. Parasitology 2007, 134, 1253-1262. 563 (47) Petronijevic, T.; Rogers, W.; Sommerville, R., Carbonic acid as the host signal for the 564 development of parasitic stages of nematodes. Int. J. Parasitol. 1985, 15, 661-667.

567 FUNDING SOURCES

568 These investigations were supported by the European Commission (PITN-GA-2011569 289377, “LegumePlus” project). 


\section{FIGURE CAPTIONS}

Figure 1. Concentrations of condensed tannins (CTs; \% of dry matter) in sainfoin and digesta/fecal samples of 9 calves in Experiment 1 using the acetone-butanol- $\mathrm{HCl}$ assay. $\mathrm{SF}=$ sainfoin pellets; $\mathrm{RU}=$ rumen; $\mathrm{AB}=$ abomasum; $\mathrm{SI}=$ small intestine; $\mathrm{LI}=$ large intestine; $F E=$ feces. Error bars are standard deviations for digesta/fecal samples $(n=9)$. No CTs were detected in control feedstuffs. Dietary level of CTs is approximately $6.3 \%$ of dry matter. Different letters indicate significant differences $(P<0.05)$.

Figure 2. Concentration and composition of condensed tannins (CTs) in sainfoin and digesta or feces of calves in Experiment 1 using in situ thiolysis. (A) CTs concentration (\% of dry matter), dietary level of CTs is approximately $1.9 \%$ of dry matter; (B) cisconfiguration (molar percentage); (C) mean degree of polymerization; (D) \% of prodelphinidins (PDs; molar percentage). $\mathrm{SF}=$ sainfoin pellets; $\mathrm{RU}=$ rumen, $\mathrm{AB}=$ abomasum; $\mathrm{SI}=$ small intestine; $\mathrm{LI}=$ large intestine; $\mathrm{FE}=$ feces. Error bars are standard deviations for digesta/fecal samples ( $\mathrm{n}=8$ except for $\mathrm{SI}=4$ and $\mathrm{LI}=2$ ). Calf \#4413 was an outlier and is represented separately $(\Delta)$. No CT were detected in control feedstuffs. Different letters indicate significant differences for CTs concentrations $(P<0.05)$.

Figure 3. Flavan-3-ol subunit (mmolar) composition of condensed tannins in sainfoin and digesta/feces of calves in Experiment 1 using in situ thiolysis. (A) terminal units; (B) extension units (BM-adducts). BM=benzyl-mercaptan. Flavan-3-ols occuring in prodelphinidins (-): GC=gallocatechin, EGC=epigallocatechin; in procyanidins (...): $\mathrm{C}=$ catechin; $\mathrm{EC}=$ =picatechin. $\mathrm{SF}=$ sainfoin pellets; $\mathrm{RU}=$ rumen; $\mathrm{AB}=$ abomasum; $\mathrm{SI}=$ small intestine; $\mathrm{LI}=$ large intestine; FE=feces. Error bars are standard deviations for digesta/fecal 
594 samples ( $n=8)$. Calf \#4413 was not included. No CTs were detected in control feedstuffs. 595 Please note the differently scaled y-axis.

596 Figure 4. Kinetics of the exsheathment of third-stage larvae of (A) Ostertagia ostertagi and 597 (B) Cooperia oncophora in the rumen of fistulated cows $(n=3)$ in Experiment 2. Control 598 feed (...) without sainfoin. SF=sainfoin silage percentage included in the ration $(40 \%$ for 599 three days; $80 \%$ for 1,3 and 5 days). Error bars are standard deviations.

600 
FIGURE GRAPHICS

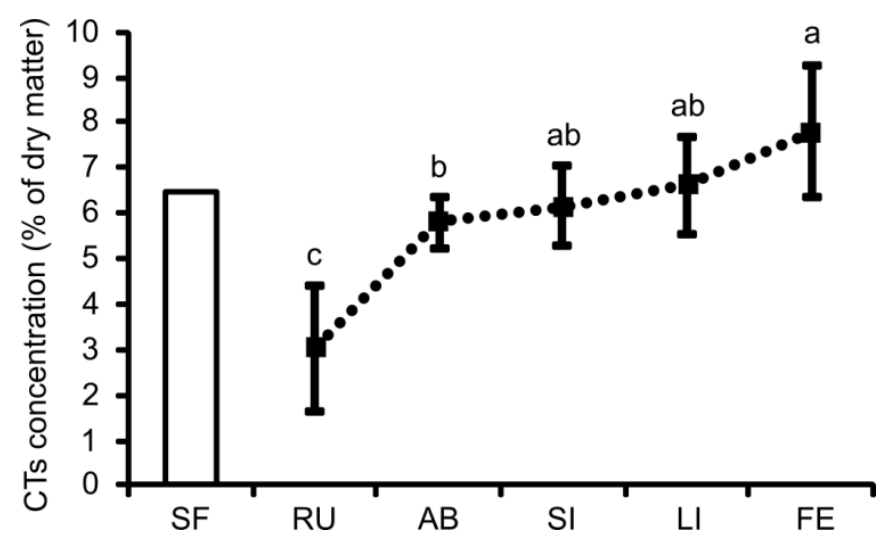

Figure 1. 
A CTs concentration ( $\%$ of dry matter)

B cis flavan-3-ols (\%) $\Delta$ :Calf \#4413
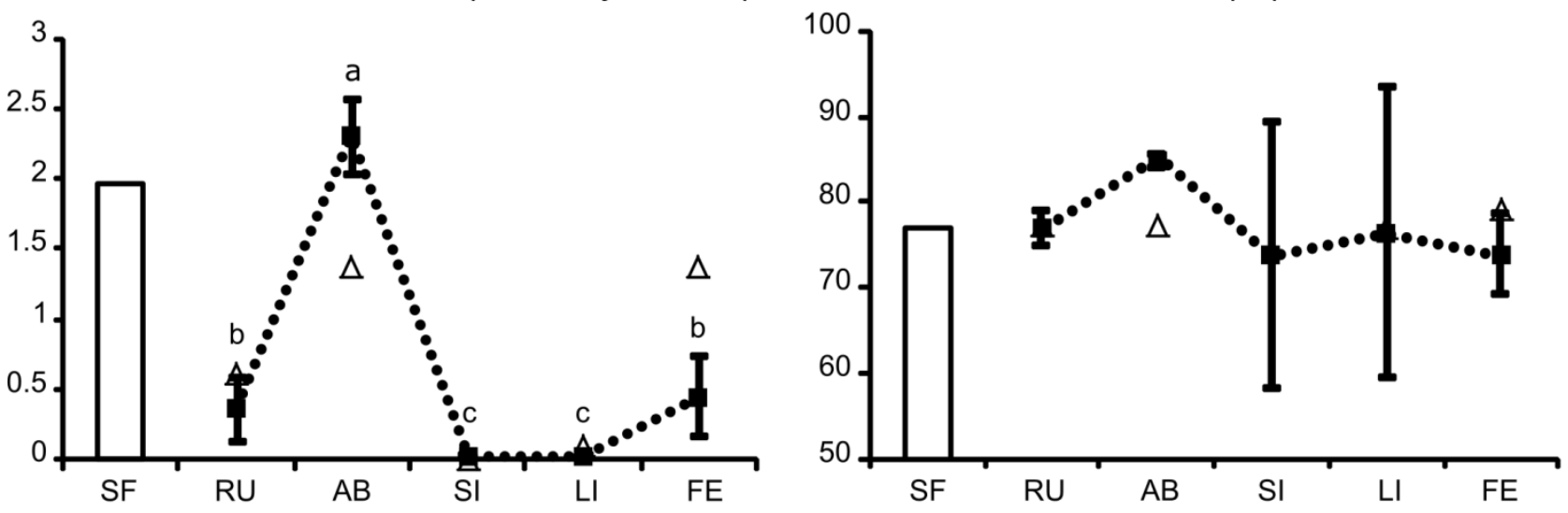

C $\mathrm{mDP}$

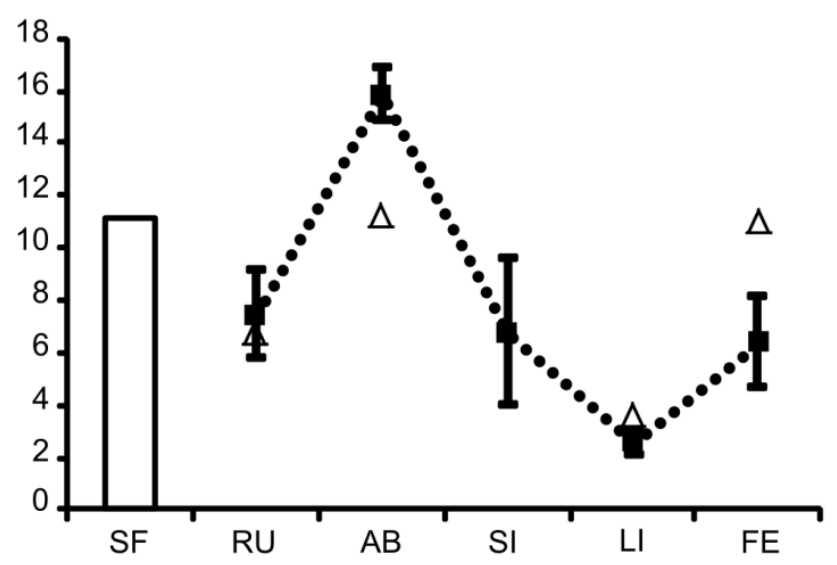

D PDs (\%)

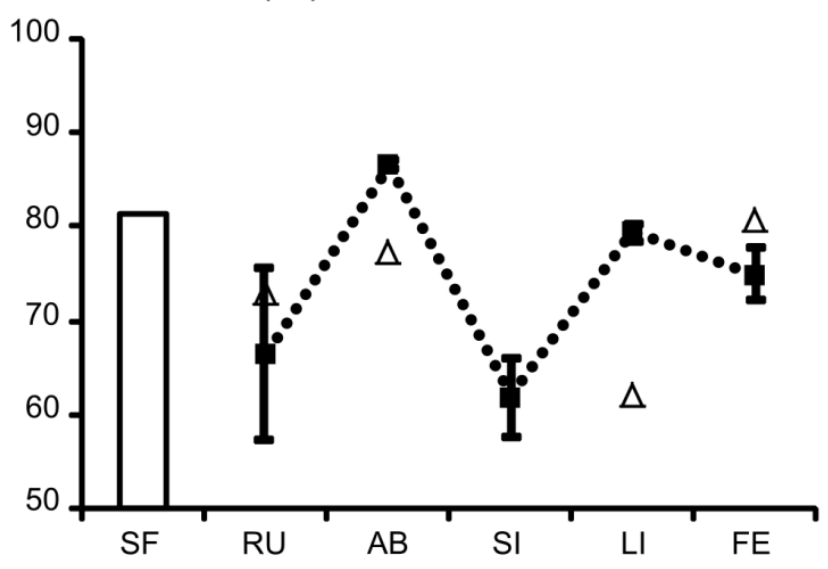

Figure 2. 
A Terminal units of CTs (mmolar)

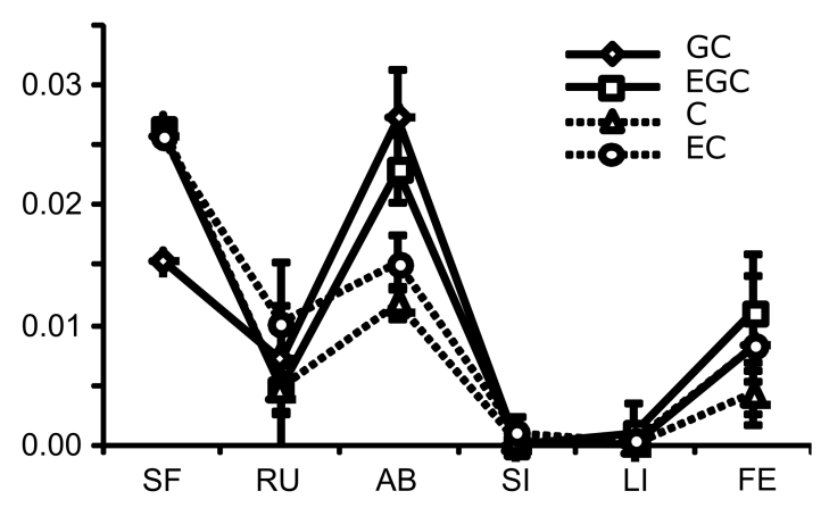

B Extension units of CTs (mmolar)

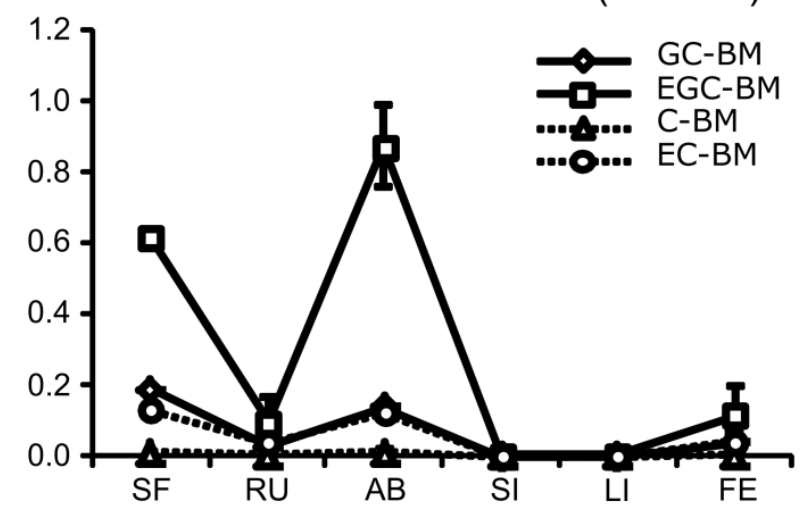

Figure 3. 
A Ostertagia ostertagi

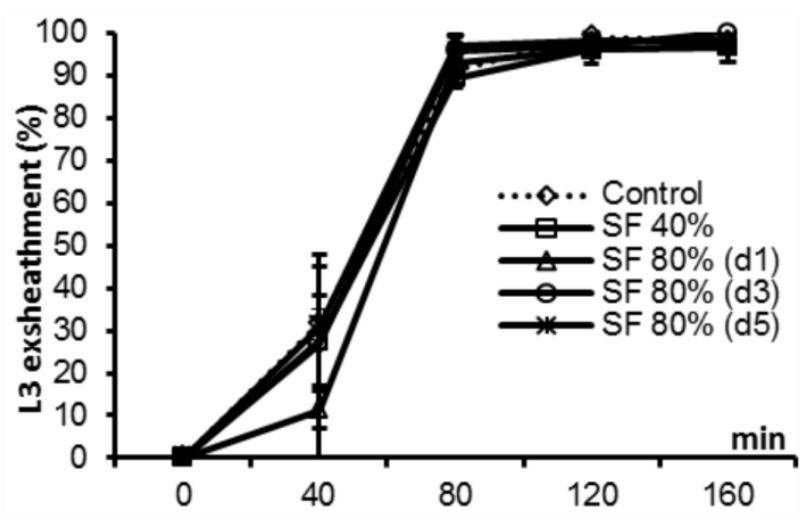

B Cooperia oncophora

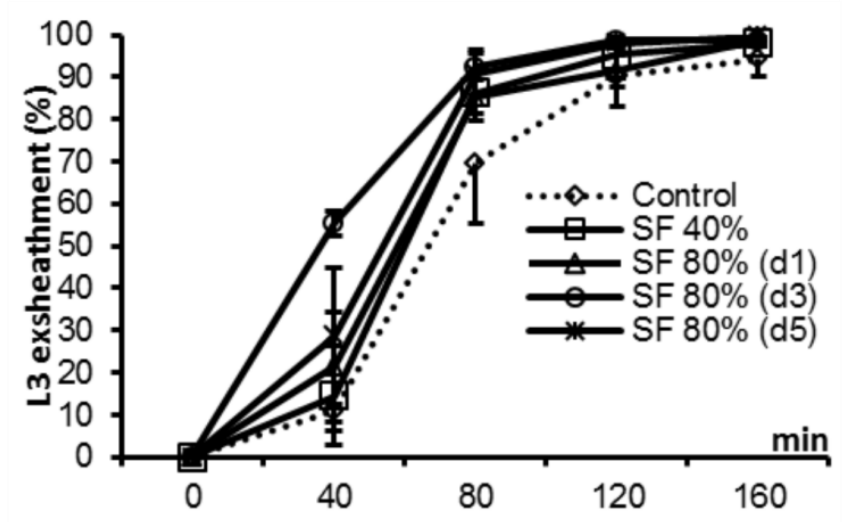

Figure 4. 


\section{Anthelmintic Activity of Condensed Tannins}
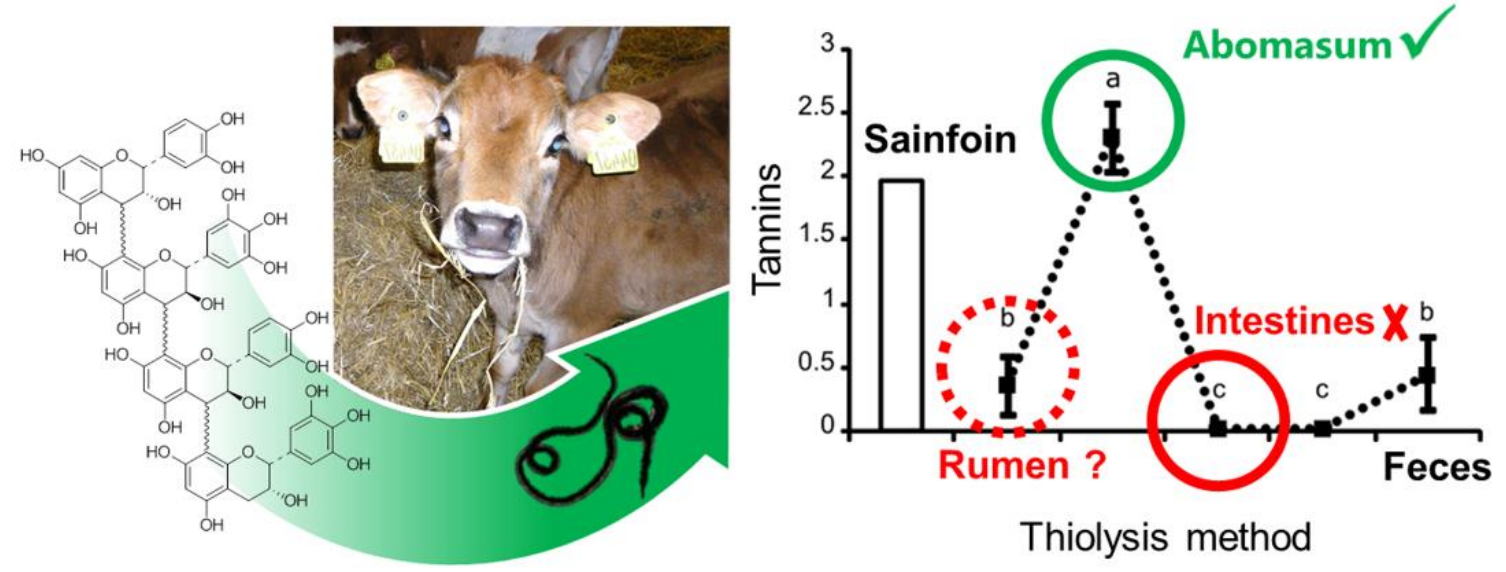

Graphic for table of contents 